\title{
A review of immune thrombocytopenic purpura: focus on the novel thrombopoietin agonists
}

This article was published in the following Dove Press journal:

Journal of Blood Medicine

20 March 2010

Number of times this article has been viewed

\author{
Meaghan Khan \\ Joseph Mikhael \\ Division of Hematology - Oncology, \\ Scottsdale, AZ, USA
}

\begin{abstract}
Immune thrombocytopenic purpura (ITP) is an autoimmune disorder that is characterized by antibody-mediated platelet destruction and decreased platelet production. ITP and its treatments have been recognized to cause diminished quality of life in those afflicted with this illness on levels comparable to other chronic diseases. The disease can be self-limiting, but in adults it often is a chronic process requiring medical intervention to maintain appropriate platelet counts and to reduce bleeding events. Many patients go on to develop disease that is refractory to current interventions. Historically, the aim of treatment has been focused on reducing the amount of antibody-mediated destruction but newer therapies have centered on the decreased platelet production. Two new medications that target production of platelets have recently been USA, Food and Drug Administration (FDA) approved for the treatment of chronic relapsing ITP. Here, we provide an overview of ITP and a comprehensive review of the newest therapies aimed at the stimulation of platelet production.
\end{abstract}

Keywords: immune thrombocytopenic purpura, therapy, thrombopoietin, romiplostim, AMG 531, eltrombopag

\section{Introduction}

Immune thrombocytopenic purpura (ITP) is an autoimmune disorder that is characterized by antibody-mediated platelet destruction and impaired platelet production causing thrombocytopenia and increased risks of bleeding. ${ }^{1}$ It remains a diagnosis of exclusion and is primarily based on the patient's history, physical examination, complete blood count, and peripheral smear. ${ }^{2}$ While childhood ITP typically presents as an acute, self-limited process, adult disease tends to be persistent with recurrent relapses often requiring medical intervention. The clinical presentation is variable. Up to $21 \%$ of adults are asymptomatic and may be diagnosed incidentally after routine blood work, yet many present with mucocutaneous bleeding, hemorrhage from other body sites, or in rare cases suffer life-threatening hemorrhage; the most serious being intracranial. ${ }^{3}$ Signs and symptoms usually correlate with platelet count levels. Normal platelet counts range from $150 \times 10^{9} / \mathrm{L}$ to $450 \times 10^{9} / \mathrm{L}$ (new recommendations suggest a lower threshold of $\left.100 \times 10^{9} / \mathrm{L}\right){ }^{4}$ yet most patients do not exhibit signs of bleeding until platelet counts are $<50 \times 10^{9} /$ L. $^{1}$

The true incidence of adult ITP has not been well established and varies based on the definition of the platelet count threshold. Most epidemiologic studies originate from Europe while data remains limited in the United States. The incidence of adult ITP has been reported to range from approximately 1.6 to 3.9 per 100,000 persons per year with a notable increased incidence with age. ${ }^{3,5,6}$ The median age of onset is 
56 years and female to male ratio is slightly greater (1.7) in those less than 60 years but is equal among older patients. , $^{3,7}$ The prevalence of this disease in the United States and Europe is estimated at 9.5 per 100,000 persons per year but has been reported up to 20 per 100,000 persons if patients over the age of 65 are included, causing significant clinical and economic impact. ${ }^{8,9}$ The morbidity and mortality risk of patients with ITP is 30\%-50\% higher than those without the disease. ${ }^{6,10}$ ITP leads to increased hospitalizations, specialty consultations, medications, and surgery in addition to decreased quality of life. ${ }^{11-13}$ Therefore, improvements in the current therapies to achieve and maintain a durable platelet count, reduce bleeding risks, and minimize treatment related toxicities remains a priority.

Although the precipitating etiology behind ITP is unclear, the pathogenesis of platelet antibody formation leading to destruction and suppressed platelet production has been well studied. Proposed mechanisms describe an intricate relationship between $\mathrm{B}$ and T-cells in the formation of antibody production. ${ }^{14,15}$ Anti-platelet antibodies arise from a limited number of B-cell clones that target platelet glycoproteins (GP) IIb/IIIa and Ib/IX. The glycoproteins are cleaved to peptides by macrophages or other antigen-presenting cells (APC) and are expressed on MHC class II molecules by way of Fcy receptors. Additionally, the APC generate new epitopes which induce activation of T-cells. This epitope-spreading is thought to play an important role in the initiation of ITP. The presentation of peptides on the APC triggers the binding of T-cell receptors (TCR) which activate $\mathrm{T}$ helper cells. The $\mathrm{T}$ helper cell then stimulates the production of cytokines (IL-2 and interferon) thus promoting B-cell differentiation and autoantibody production. ${ }^{16}$ The antibodies opsonize the platelets which are then destroyed by macrophages, primarily in the spleen. These antibodies also bind to megakaryocytes which can inhibit maturation and platelet production. ${ }^{14,16,17}$ Although testing for these antibodies is not considered standard of care, some studies propose that autoantibody detection in patients suffering from ITP may correlate with disease severity and prognosis. Further evaluation is needed in this regard..$^{18,19}$

\section{Indications for treatment and first line agents}

Treatment is indicated in those with platelet counts $<30 \times 10^{9} / \mathrm{L}$, or in those with counts $<50 \times 10^{9} / \mathrm{L}$ with evidence of mucocutaneous bleeding or with risk factors for bleeding. ${ }^{2}$ The goals of therapy are aimed at maintaining appropriate platelet counts and reducing the risk of bleeding while minimizing treatment-related toxicities. Initial therapy is usually focused on inhibition of antibody platelet destruction and includes treatments such as corticosteroids, IVIG, and anti-RhD immunoglobulin (Table 1). ${ }^{20,21}$ Prednisone ( $1-4 \mathrm{mg} / \mathrm{kg} /$ day) is the standard initiation therapy with nearly a $66 \%$ complete or partial response rate in the first $1-2$ weeks. ${ }^{2,20}$ However, relapse is often seen in adult chronic disease and adverse effects of long-term use of corticosteroids needs to be considered. IVIG ( $1 \mathrm{~g} / \mathrm{kg} /$ day for $1-2$ days) is often reserved for those who do not respond to corticosteroids or other similar therapies and can be used when a rapid or temporary increase in platelets is needed. The results, while effective in approximately $85 \%$ of patients, are transient and often last an average of 3-4 weeks. ${ }^{22}$ Anti-D immunoglobulin $(50 \mu \mathrm{g} / \mathrm{kg})$ is approximately $70 \%$ effective in Rh-positive, nonsplenectomized patients. ${ }^{23}$ It also has a transient effect

Table I Available initial treatment options for patients with ITP, including splenectomy

\begin{tabular}{|c|c|c|c|c|c|c|}
\hline Therapy & Dose & $\begin{array}{l}\text { Time to peak } \\
\text { response (days) }\end{array}$ & $\begin{array}{l}\text { Response duration } \\
\text { (average) }\end{array}$ & $\begin{array}{l}\text { Initial } \\
\text { responses (\%) }\end{array}$ & $\begin{array}{l}\text { Complete } \\
\text { remission (\%) }\end{array}$ & Adverse effects \\
\hline $\begin{array}{l}\text { Oral } \\
\text { corticosteroids }\end{array}$ & $1-4 \mathrm{mg} / \mathrm{kg} / \mathrm{d}$ & 28 & $2-6$ weeks & 66 & 16 & $\begin{array}{l}\text { Hypercortisolism: } \\
\text { diabetes, infections, } \\
\text { osteoporosis }\end{array}$ \\
\hline $\begin{array}{l}\text { Intravenous } \\
\text { immunoglobulin }\end{array}$ & $\begin{array}{l}0.4 \mathrm{~g} / \mathrm{kg} / \mathrm{d} \times 5 \\
\mathrm{lg} / \mathrm{kg} / \mathrm{d} \times 2\end{array}$ & $2-4$ & $3-4$ weeks & $75-92$ & $50-65$ & $\begin{array}{l}\text { Headache, lethargy, } \\
\text { fever, photophobia }\end{array}$ \\
\hline $\begin{array}{l}\text { Anti-D } \\
\text { immunoglobulin }\end{array}$ & $50 \mu \mathrm{g} / \mathrm{kg} / \mathrm{d} \times \mathrm{I}$ & 3 & 3 weeks & 70 & 33 & $\begin{array}{l}\text { Mild expected } \\
\text { extravascular } \\
\text { hemolysis, fever } \\
\text { headache, nausea, } \\
\text { chills, dizziness }\end{array}$ \\
\hline Splenectomy & & $<10$ & $>7$ years & $60-86$ & 60 & $\begin{array}{l}\text { Surgical } \\
\text { complications, } \\
\text { sepsis, thrombosis }\end{array}$ \\
\hline
\end{tabular}

Notes: Current first line therapies and splenectomy for the initial treatment of ITP.,3,17,18 
on platelets and is utilized when a temporary increase in platelets or temporary deferral of splenectomy is warranted. ${ }^{24}$ Although these therapies are often effective, their duration tends to be short-lived. Each of these treatments aims at creating a complete or partial remission in thrombocytopenia and do not appear to change the natural history in the disorder. Due to the relapsing, chronic nature of adult ITP, frequent use of these medications may occur. Long-term side effects of each agent must be considered and is a factor that patients often refer to when rating their quality of life. ${ }^{13,25}$

\section{Second line therapy}

While most patients have transient responses after initial therapy, some will have relapsing disease that with time, have less response to the preliminary medications. Traditionally splenectomy has been the most successful second line therapy with the highest rate of durable platelet response with long-term follow-up. After splenectomy, 66\% of patients acquire normal platelet counts that are durable up to 7.3 years following the procedure. ${ }^{26}$ Overall failure rates 5 years post-splenectomy are approximately $28 \%$. Short-term failure occurs in $8.2 \%$ of patients while the long-term relapse rate is near 44 per 1000 patient years with most occurring in the first two years post-operatively. ${ }^{27}$ Splenectomy remains an invasive procedure that carries some operative risks. Mortality rates of $1 \%$ and $0.2 \%$ post-open laparotomy and laparoscopic splenectomy, respectively, have been reported. ${ }^{26}$ Small lifetime risks of serious infections are known and some patients are not candidates or may prefer not to undergo surgery. ${ }^{27}$ Alternative therapies are indicated in those not able to receive a splenectomy, in those who do not respond to the splenectomy, or those that have relapse of disease post-operatively.

\section{Treatment of chronic refractory ITP}

Chronic refractory disease occurs in less than $10 \%$ of ITP patients and is defined as disease that persists for greater than 12 months. ${ }^{4,10}$ It is characterized as failure to achieve a response post-splenectomy requiring continuous treatments to minimize risk of clinically significant bleeding. Diagnosis can only be made after all other causes for thrombocytopenia have been eliminated. ${ }^{4}$ Patients who go on to have refractory disease have nearly a 4 -fold increase in the risk of death. ${ }^{10}$

Therapeutic agents intended for use in refractory cases have included high dose corticosteroids such as dexamethasone, or agents such as danazol, azathioprine, cyclosporine, cyclophosphamide, vinca alkaloids, and combination chemotherapy. Recent data suggests the combination of individual immunosuppressant agents may have an additional benefit in refractory patients. ${ }^{28}$ However, each treatment carries its own side effects and evidence is still lacking from randomized clinical trials. Therefore use should be limited to those with refractory disease with appropriate clinical judgment behind their application. ${ }^{2,20}$

Minimal work had been done in the area of immunotherapy for ITP until the development of anti-CD20 antibody. Rituximab, a monoclonal anti-CD20 antibody, has been recently introduced as a possible therapeutic agent for the treatment of ITP. Rituximab targets antibody producing B lymphocytes and lyses the culprit cell behind the autoantibody production, therefore proving to be a potential tool in the treatment of ITP. Several studies have been performed to test the efficacy and safety of Rituximab in the treatment of ITP. Collaborative review of 19 small studies reported an overall response rate of $62.5 \%$ with a mean duration of 10.5 months in patients who received 4 weekly infusions of $375 \mathrm{mg} / \mathrm{m}^{2}$. Sixty percent of patients in the largest of these studies reported mild infusion-related side effects and approximately 7\% reported unfavorable outcomes. ${ }^{29}$ A recent cohort analyzing 23 patients revealed a less promising outcome with only a $48 \%$ response to Rituximab, yet reported a higher rate of serious adverse events $(17 \%){ }^{30}$ A randomized study comparing Rituximab plus Dexamethasone or Dexamethasone alone in ITP yielded a favorable platelet count response with the combination therapy without worsening the safety profile, suggesting this dual treatment as a reasonable option prior to splenectomy. ${ }^{31}$ Further large randomized controlled trials are still needed to investigate the utility of Rituximab in ITP.

\section{Thrombopoietin (TPO) and the development of TPO agonists}

For many years, focus has been on the elimination and suppression of the auto-antibodies that cause platelet destruction, but a newer shift has targeted the mechanism behind the decreased platelet production in attempts to enhance platelet counts. In patients with ITP, it has been well documented that auto-antibodies also interfere with megakaryocyte maturation and platelet production. ${ }^{32}$ Thrombopoietin (TPO) is a glycoprotein primarily produced in the liver that has been recognized as the principal cytokine regulator of megakaryopoiesis and platelet production. ${ }^{33}$ TPO acts by binding to its c-MPL receptor (a receptor present on multilineage human myeloid progenitors) and triggering a signaling cascade via 
JAK2 and STAT5 signal transduction resulting in increased megakaryocyte proliferation and differentiation, thus enhanced platelet production. ${ }^{33-35}$ TPO levels in patients with ITP are usually normal or only mildly elevated, but much less than expected for the degree of thrombocytopenia. In fact, TPO levels were markedly lower than levels found in patients with thrombocytopenia from chemotherapy or bone marrow failure. ${ }^{36}$ One explanation suggests that patients with ITP have a rapid clearance of TPO either by binding to platelets undergoing rapid consumption or by binding to increased megakaryocytes in this disease. ${ }^{37}$ This finding prompted investigation into methods to enhance platelet production.

In 1994, thrombopoietin was successfully cloned leading to the production of two new therapies: recombinant human TPO (rhTPO), a glycosylated molecule identical to endogenous TPO, and recombinant human megakaryocyte growth and development factor (MGDF) which is a truncated nonglycosylated form of TPO, conjugated to polyethylene glycol (PEG-rHuMGDF). ${ }^{38,39}$ Both agents were able to increase platelet counts in normal subjects as well as patients undergoing chemotherapy. ${ }^{40}$ In an initial clinical study of PEG-rHuMGDF in ITP, results were promising with a $75 \%$ response rate. ${ }^{41}$ However, a subsequent larger clinical trial revealed this agent was associated with prolonged thrombocytopenia. Data indicated the development of antibodies to PEG-rHuMGDF in healthy volunteers that cross-reacted to endogenous TPO, which caused severe persistent thrombocytopenia in select patients. These findings required its removal from clinical studies. ${ }^{42}$

Despite this setback, these agents demonstrated efficacy in increasing the platelet count in thrombocytopenic patients by targeting the TPO receptor, therefore efforts next focused on the development of TPO receptor agonists that do not stimulate this antibody production. Researchers reviewed peptide libraries to find random, unrelated peptide and nonpeptide molecules that could stimulate TPO receptors without causing antibody production. ${ }^{43,44}$ This strategy led to the development of two TPO mimetic drugs, romiplostim and eltrombopag, which have no sequence homology with endogenous thrombopoietin. ${ }^{37,45}$ Both agents work by mimicking thrombopoietin and act by binding to or near the TPO receptor, stimulating megakaryopoiesis and platelet production. The quality of multiple randomized studies as outlined below for both romiplostim and eltrombopag have led to recent FDA approval of these agents for use in refractory ITP both before and after splenectomy, and are under continuous clinical investigations at this time.

\section{Romiplostim (AMG 53 I)}

Romiplostim (AMG 531; Nplate $^{\circledR}$ ) is a thrombopoietin receptor agonist that received FDA approval in August 2008 for the treatment of thrombocytopenia in patients with chronic ITP who have had insufficient response to steroids, IVIG or splenectomy. ${ }^{45-47}$ It is comprised of an Fc-peptide fusion protein (peptibody) containing disulfide-bonded human IgG1 heavy chain, and kappa light chain constant regions making up an $\mathrm{Fc}$ component which extends the half-life of the molecule to $120-160$ hours (Figure 1). ${ }^{48}$ This component is linked with two identical peptide sequences containing thrombopoietin receptor-binding domains making it capable of binding and activating the TPO receptor (c-MPL), thus stimulating megakaryopoiesis and platelet production. ${ }^{46,49}$ This structure has no sequence homology with human TPO and therefore does not develop crossreacting antibodies to thrombopoietin. ${ }^{45,50}$

Safety and tolerance were analyzed and deemed adequate in a preliminary double-blinded, randomized, placebo-controlled human trial using a single injection of AMG 531 at varied doses allowing for Phase I and II trials of romiplostim. ${ }^{49,51-53}$ The Phase I study administered two injections of romiplostim to 24 patients at incremental doses to assess safety and tolerability as well as to determine which dose that would achieve a platelet count within the targeted range of $50 \times 10^{9} / \mathrm{L}$ to $450 \times 10^{9} / \mathrm{L}$. Platelet response did not reach the target in patients who received doses less than $3 \mu \mathrm{g} / \mathrm{kg}$, while 7 patients receiving 3, 6 , or $10 \mu \mathrm{g} / \mathrm{kg}$ reached or exceeded the goal. The most frequently reported adverse events were contusions and ecchymosis (67\%) and mild to moderate headache (46\%). No major adverse events were attributed to the use of romiplostim. One patient, however, reported a transient decrease in platelets after discontinuation of the medication. ${ }^{52}$

The Phase II study then randomly assigned 21 patients to receive incremented doses of AMG 531 once a week

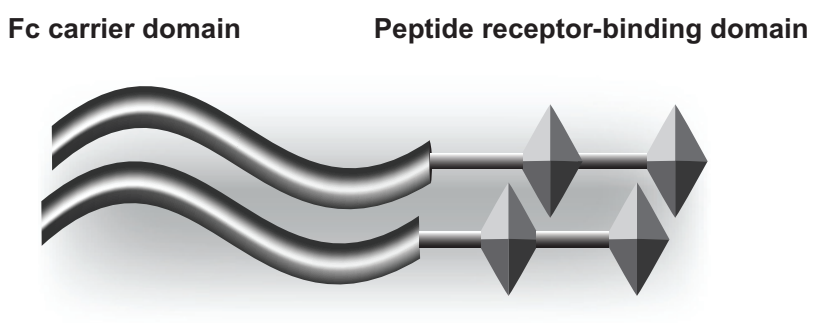

Figure I Structure of romiplostim. ${ }^{48}$

Notes: The left-hand side of the diagram shows the $\lg G$ Fc carrier portion of the molecule. The right-hand side shows the peptide that binds to the thrombopoietin receptor (Mpl). 
for 6 weeks. Platelet counts increased in most patients with the targeted goal being met or exceeded in 12 of 16 patients receiving romiplostim. The most frequently reported adverse events were contusions and ecchymosis (59\%), expistaxis (41\%), and mild to moderate headache (29\%). During the study, one patient receiving romiplostim suffered a severe adverse event described as vaginal bleeding with transient worsening of thrombocytopenia 19 days after discontinuation of romiplostim..$^{52}$

The ongoing rate of platelet destruction did not appear to be affected by romiplostim, as all patients who received the drug had a platelet count that returned to baseline (or transiently below baseline) after discontinuation of therapy. These preliminary short-term studies indicated that romiplostim causes a dose-dependent increase in platelet counts that is generally well-tolerated with no anti-TPO or anti-AMG 531 antibodies detected. This prompted the need for further investigation into individual dose adjustment therapy, as well as the outcome of long-term therapy and its ability to maintain a durable platelet response.

Two parallel Phase III randomized, placebo-controlled, double-blind clinical trials assessed the efficacy, as measured by a durable platelet response of $\geq 50 \times 10^{9} / \mathrm{L}$ for 6 or more of the last 8 weeks, safety, and optimal dosing in the long-term administration of romiplostim. ${ }^{54}$ Sixty-three splenectomized and 62 nonsplenectomized patients with a mean of 3 platelet counts $\leq 30 \times 10^{9} / \mathrm{L}$ were enrolled. A durable platelet response was achieved in 16 of 42 splenectomized patients versus 0 of 21 placebo, and by 25 of 41 nonsplenectomized patients versus 1 of 21 placebo. The overall platelet response (transient or durable) was $79 \%$ of splenectomized and $88 \%$ of nonsplenectomized patients given romiplostim compared to $0 \%$ and $14 \%$ of those receiving placebo, respectively. In addition to monitoring platelet response, patient capacity to reduce or discontinue concurrent therapy during this trial was assessed. Eighty-seven percent of patients receiving romiplostim were able to reduce or discontinue concomitant therapy compared to $38 \%$ of the placebo group, while maintaining a durable platelet response. ${ }^{5}$

Adverse events were reported in $95 \%$ of those receiving placebo and $100 \%$ of those receiving romiplostim, but the majority were considered to be mild to moderate. Serious adverse events were noted in four patients, two thought to be romiplostim related. One romiplostim-assigned patient developed thrombosis while another splenectomized patient with a baseline elevated bone marrow reticulin developed further reticulin after 7 weeks of therapy. The levels did return to baseline 14 weeks after discontinuation of the medication. ${ }^{54}$
Patients who completed this or other AMG 531 studies were then eligible to enroll in an open-label extension study with weekly injections and dose adjustment based on individual platelet counts over a longer period..$^{55}$ To date, this study has investigated 142 patients undergoing treatment with romiplostim for up to 156 weeks, (mean 69 weeks) using a dose-adjusted weekly administration to achieve a sustainable target platelet count of 50 to $250 \times 10^{9} / \mathrm{L}$. After 3 weeks of therapy, $51 \%$ of patients had demonstrated a targeted platelet response while $87 \%$ of patients had at least one targeted response during the study. Long-term results of this study are still pending. This trial did demonstrate a decreased proportion of responses in splenectomized patients and although goal platelet counts were reached, these were generally less than in the nonsplenectomized patients. This discrepancy raises a question of whether romiplostim could be used to avoid splenectomy and this is currently being investigated. ${ }^{55}$ The average weekly dose was $5.9 \mu \mathrm{g} / \mathrm{kg}$; somewhat higher than the $2.5 \mu \mathrm{g} / \mathrm{kg}$ seen in the Phase III trials. Rescue medications were needed in $36 \%$ of patients at some point during the study, but use decreased with time. Eighty-four percent of patients requiring concurrent treatment at baseline were able discontinue $(50 \%)$ or decrease $(34 \%)$ their medications by the time of study cut-off. These results were reinforced by another similar study which pooled data from these 2 phase III trials and found that only $14 \%$ of patients receiving romiplostim required IVIG rescue therapy compared to $50 \%$ in the placebo group. ${ }^{56}$

The most frequently reported adverse events were headache, contusion, and expistaxis. Nineteen serious adverse events were noted in 13 patients including increased bone marrow reticulin, vaginal hemorrhage, deep venous thrombosis, and monoclonoal gammopathy of undetermined significance. Bleeding events decreased, however, from $42 \%$ to $29 \%$ from the first 24 weeks to the next. ${ }^{55,57}$ Fourteen severe bleeding events occurred, but no deaths were reported from bleeding. Twelve thrombotic events were reported in 7 patients; 6 of the 7 patients had known risk factors for thrombosis prior to romiplostim. There were 3 deaths reported during this study, none of which were attributed to romiplostim therapy.

During this extended study, a total of 16 patients underwent evaluation to assess romiplostim's effect on bone marrow reticulin. Eight baseline biopsies were obtained, with 5 of 7 remaining negative after treatment. Spontaneous reports from 8 additional patients revealed increased bone marrow reticulin after therapy. Follow up bone marrows were completed in 2 of these patients upon discontinuation 
of romiplostim, 1 of which demonstrated improvement. No clinical symptoms were reported in any of the cases, however. ${ }^{55}$ Reticulin is a normal component of the bone marrow and can be found in healthy subjects in small amounts. Increases can occur in many benign and malignant conditions and it is proposed that thrombopoietic agents may reversibly increase bone marrow reticulin by releasing transforming growth factor (TGF)-B from the increased number of bone marrow megakaryocytes. ${ }^{58,59}$ Further investigations into the relationship between bone marrow fibrosis and romiplostim have been performed in animal and human studies, both of which demonstrated dose-dependent increases in bone marrow reticulin that resolved after discontinuation of therapy with time. ${ }^{59}$ To date, no progression to myelofibrosis has been reported in any patient receiving TPO mimetic therapy. ${ }^{60}$

Overall, the current studies on the safety and efficacy of romiplostim suggest that romiplostim may in fact be a welltolerated treatment, and perhaps even a maintenance therapy for patients with chronic refractory ITP (Table 2). In general, patients reported a decrease in bleeding events over time, as well as a reduced number of severe bleeding events. This suggests that the platelet count responses to romiplostim are of clinical benefit, thus making it a useful therapy in patients with chronic, refractory ITP.

The recommended starting dose for romiplostim is $1 \mu \mathrm{g} / \mathrm{kg} /$ week up to a maximum dose of $10 \mu \mathrm{g} / \mathrm{kg} /$ week to achieve and maintain a platelet count of $\geq 50 \times 10^{9} / \mathrm{L}$, as necessary, to reduce the risk of bleeding. It should not be administered if platelet counts are $>400 \times 10^{9} / \mathrm{L}$ and should be discontinued if, after 4 weeks, the platelet count does not respond to maximum dosage. ${ }^{61,62}$ It is currently available in single use vials of $250 \mu \mathrm{g}$ or $500 \mu \mathrm{g}{ }^{63}$

\section{Eltrombopag (SB-497 I I 5)}

Eltrombopag (SB-497115; Promacta) is an oral, low molecular weight, nonpeptide thrombopoietin receptor agonist that received FDA approval in November 2008 for the treatment of chronic refractory ITP in people who have had insufficient response to corticosteroids, IVIG or splenectomy (Figure 2). ${ }^{64}$ While its effects are similar to romiplostim, its mechanism differs in that it binds to the transmembrane domain of the thrombopoietin receptor but does not compete for the same binding site as endogenous TPO or romiplostim. Instead, it activates the JAK2 and STAT5 signaling pathway to stimulate proliferation and differentiation of megakaryocytes, thus increasing platelet production. ${ }^{65}$

Pre-clinical activity of eltrombopag confirmed its selective nature for TPO receptors in humans with a resultant increase in platelet production in vivo without affecting the overall platelet function. ${ }^{66,67}$ Phase I clinical studies in volunteers with normal platelet counts and in patients with thrombocytopenia secondary to hepatitis $\mathrm{C}$ infections, including a placebo-controlled

Table 2 Comparison of characteristics of romiplostim and eltrombopag

\begin{tabular}{|c|c|c|}
\hline & Romiplostim & Eltrombopag \\
\hline Route of administration & Once weekly subcutaneous injection & Once daily oral \\
\hline Starting dose & I $\mu g / \mathrm{kg} /$ week & $50-75 \mathrm{mg} /$ day \\
\hline Efficacy & $\begin{array}{l}\text { Platelet count increases seen at } 5 \text { days; } \\
\text { peak at day } 12-15\end{array}$ & $\begin{array}{l}\text { Platelet count increases seen at } 7 \text { days; } \\
\text { peak at day } 15\end{array}$ \\
\hline \multicolumn{3}{|l|}{ Response rates: } \\
\hline Phase II & $79 \%$ & $\begin{array}{l}70 \% 50 \mathrm{mg} \\
81 \% 75 \mathrm{mg}\end{array}$ \\
\hline Phase III & $\begin{array}{l}\text { 79\% Splenectomized } \\
88 \% \text { Nonsplenectomized }\end{array}$ & $66 \% * 50-75 \mathrm{mg} * *$ \\
\hline Extension studies & $87 \%$ Transient response & $79 \%$ transient response \\
\hline $\begin{array}{l}\text { Duration of platelet response after } \\
\text { treatment discontinuation }\end{array}$ & Platelets return to baseline within 2 weeks & $\begin{array}{l}\text { Platelets return to baseline within } \\
2 \text { weeks }\end{array}$ \\
\hline $\begin{array}{l}\text { Effect of previous splenectomy on } \\
\text { durable platelet response }\end{array}$ & $\begin{array}{l}\text { Slightly more effective if nonsplenectomized } \\
(51 \% \text { vs } 31 \%)\end{array}$ & No difference \\
\hline Common reported adverse events & $\begin{array}{l}\text { Headache, contusion, fatigue, expistaxis, } \\
\text { arthralgia }\end{array}$ & $\begin{array}{l}\text { Headache, contusion, nausea, } \\
\text { nasopharyngitis }\end{array}$ \\
\hline Other adverse events & Transient bone marrow reticulin deposition & $\begin{array}{l}\text { Elevated liver enzymes, possible bone } \\
\text { marrow reticulin deposition }\end{array}$ \\
\hline Presence of cross-reactive antibodies & No & No \\
\hline
\end{tabular}

Notes: $* 59 \%$ response with $50 \mathrm{mg}$ and additional $29 \%$ response when dose increased to $75 \mathrm{mg}$. ${ }^{*}$ No statistical difference between splenectomized and nonsplenectomized patients. Characteristics of romiplostim and eltrombopag derived from clinical trials..$^{50,51,66,67}$ 


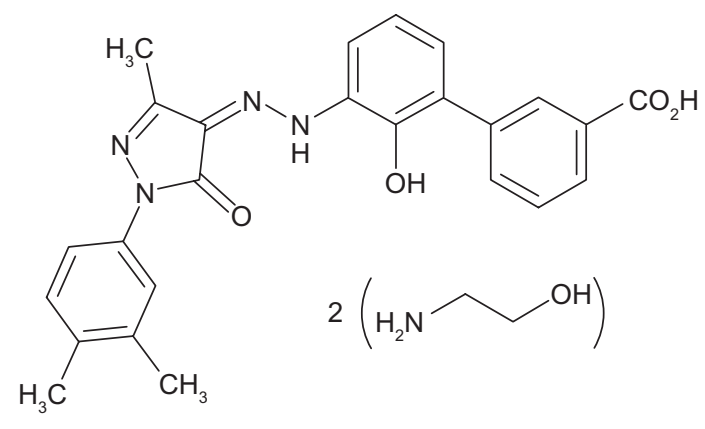

Figure 2 Structure of eltrombopag. ${ }^{60}$

Notes: Molecular formula $\mathrm{C}_{25} \mathrm{H}_{22} \mathrm{~N}_{4} \mathrm{O}_{4} \cdot 2\left(\mathrm{C}_{2} \mathrm{H}_{7} \mathrm{NO}\right)$. Eltrombopag is an orally bioavailable, low molecular weight, synthetic, nonpeptide thrombopoietin receptor agonist.

clinical trial in adults assessing the platelet response and tolerability of eltrombopag, have been performed. ${ }^{44}$ Seventythree healthy men with similar demographics were randomized to receive oral eltrombopag over a 10 day period with doses ranging from $5 \mathrm{mg}$ to $75 \mathrm{mg}$. The greatest result occurred in those receiving $50 \mathrm{mg}$ and $75 \mathrm{mg}$ daily, achieving platelet responses greater than $20 \%$ above baseline. All platelet counts returned to baseline 12 days after the last dose was administered. Adverse effects did not differ between treatment and placebo groups and were not dose-related. ${ }^{6}$

Phase II trials aimed to determine whether eltrombopag could safely increase platelet counts and reduce bleeding events in patients with chronic refractory ITP. A multicenter, double-blind, randomized, placebo-controlled trial evaluated the effects of once daily oral administration of eltrombopag. ${ }^{69}$ The study randomized 117 patients who had received at least one previous treatment for ITP and had a platelet count of $<30 \times 10^{9} / \mathrm{L}$ into groups to be given $30 \mathrm{mg}, 50 \mathrm{mg}$, or $75 \mathrm{mg}$ of eltrombopag per day. Response was defined as a platelet count of $\geq 50 \times 10^{9} / \mathrm{L}$ by day 43 . The greatest results were seen in the latter two groups as $81 \%$ of patients given $75 \mathrm{mg}$ and $70 \%$ of those given $50 \mathrm{mg}$ achieved the targeted platelet count and had decreased incidence of bleeding. Platelet counts returned to baseline once the therapy was discontinued and analysis revealed there was no difference in response between splenectomized and nonsplenectomized patients. Adverse event incidence and severity were similar across all study groups including placebo. The most common of these events reported was mild to moderate headache. Two patients receiving $75 \mathrm{mg}$ doses had elevations in aspartate aminotransferase. An FDA report on eltrombopag revealed that 19 of 117 patients exposed to eltrombopag had bone marrow examinations, 7 of which discovered fibrosis. ${ }^{58}$ This study determined that $50 \mathrm{mg}$ and $75 \mathrm{mg}$ were effective for short-term treatment of chronic ITP.
With the intention of improving platelet counts, decreasing bleeding events, yet reducing therapy-related toxicities, the $50 \mathrm{mg}$ daily dose of eltrombopag was chosen for further investigation of efficacy, safety, and tolerability in the Phase III clinical trials. ${ }^{70}$ Efficacy of a dose increase to $75 \mathrm{mg}$, if needed, was also evaluated. One hundred and fourteen patients, naïve to TPO mimetics, were randomized in a double-blind, placebo-controlled study to receive eltrombopag at $50 \mathrm{mg}$. The primary endpoint was a platelet response to $\geq 50 \times 10^{9} / \mathrm{L}$ by day 43 . An increase to $75 \mathrm{mg}$ was allowed after 3 weeks in those whose platelet counts had not achieved the target. Fifty-nine percent of the patients receiving eltrombopag met the primary target and demonstrated reduced symptoms of bleeding. Of the 74 patients administered eltrombopag, 34 patients required dose increases to $75 \mathrm{mg}$ with 10 responses (29\%). In all patients, platelet counts slowly returned to baseline within 2 weeks of therapy completion and, as expected, bleeding events increased with decreasing platelet counts. Platelet count improvements were independent of the use of concurrent ITP therapy, splenectomy, age, or baseline platelet count. Adverse events were similar between placebo and treatment groups with the exception of more nausea and vomiting reported in the treatment group. No deaths or thrombosis were reported. Six treatment and 1 placebo patient had elevation of serum transaminase concentrations to twice the normal limit with 1 patient withdrawing from the study due to abnormal hepatic function. Two patients classified as nonresponders to eltrombopag reported gastrointestinal and cerebral hemorrhage. New cataracts were reported in 3 patients receiving treatment and 1 placebo patient, while progression of existing cataracts occurred in 2 treatment patients and 1 placebo patient. Pre-clinical studies also revealed risk of cataract formation in rats receiving eltrombopag. ${ }^{66}$

Ongoing analysis continues in the treatment of chronic ITP with eltrombopag. An open-label study designed to evaluate the long-term safety and clinical benefit in patients who have already been administered eltrombopag called EXTEND is being conducted. To date, two hundred seven patients have been treated with eltrombopag with doses starting at $50 \mathrm{mg}$, but with the flexibility for titration up to $75 \mathrm{mg}$ or down to $25 \mathrm{mg}$ based on platelet counts. Long-term effects were similar to those in the shorter studies. Seventy-nine percent of patients reached target platelet counts of $\geq 50 \times 10^{9} / \mathrm{L}$, while $24 \%$ were able to maintain that level for $\geq 25$ consecutive weeks. ${ }^{71}$ Patients whose platelet counts fluctuated underwent evaluation of intermittent treatment with eltrombopag with outcomes suggesting that repeated use can provide predictable and consistent responses from previous administration. ${ }^{72}$ 
Data from 165 chronic ITP patients both refractory (68) and nonrefractory (97) have also been assessed. Overall, 75\% of refractory and $81 \%$ of nonrefractory had platelet count responses $\geq 50 \times 10^{9} / \mathrm{L}$ with no statistical difference between the two. Both groups had diminished bleeding episodes during treatment as well. ${ }^{73}$ Review of patients in the EXTEND study who did not achieve platelet counts $\geq 50 \times 10^{9} / \mathrm{L}$, demonstrated that they still receive clinical benefit from the medication in terms of doubling platelet counts, reducing concurrent medications (up to $80 \%$ were able to reduce) and reducing bleeding symptoms. ${ }^{74,75}$

A second Phase III trial, RAISE, evaluated the longterm efficacy and safety of eltrombopag in 197 patients in a randomized, double-blind, placebo-controlled study over 6 months, with the primary end point being the odds of platelet response during the treatment period. Of the 197 enrolled, 135 patients were assigned to eltrombopag at $50 \mathrm{mg}$ with the ability to increase or decrease the dose based on platelet counts. ${ }^{76}$ Those receiving the medication were calculated to be eight times more likely to achieve a targeted response. Concurrent therapy was reduced in 59\% of those receiving eltrombopag and patients responded to treatment despite splenectomy status, previous platelet counts, or concomitant medications used. Adverse events were similar to previous studies and were comparable between placebo and treatment groups with the most common reported adverse event being mild to moderate headache. No evidence of bone marrow fibrosis was detected in clinical or laboratory assessment. Serum hepatobiliary abnormalities were detected in $13 \%$ of patients receiving eltrombopag. ${ }^{76}$

Eltrombopag is metabolized in the liver and may be associated with hepatotoxicity. ${ }^{65}$ In fact, the FDA issued a black box warning regarding this risk, recommending initial and routine monitoring of liver function tests. ${ }^{64}$ Patients with known hepatic impairment need to be monitored closely with administration of this medication and initial dosing should be reduced to $25 \mathrm{mg} /$ day. ${ }^{65}$ Clinical studies in healthy volunteers indicate that eltrombopag is not an inducer or inhibitor of the cytochrome P (CYP) isoenzymes, but no studies have evaluated the effects other CYP isoenzyme inducers or inhibitors have on its metabolism. ${ }^{64}$ In vitro studies have suggested that it is an inhibitor of the UDP-glucuronosyltransferase (UGT) isoenzymes (enzymes responsible for metabolizing medications such as acetaminophen, narcotics, and NSAIDs), but again, no clinical studies comparing co-administration have been performed. ${ }^{64}$

Food and antacids affect the pharmacokinetics of eltrombopag. ${ }^{77}$ It has a similar structure to some metal chelators and can therefore bind to metals such as zinc, copper, magnesium, and calcium. Two single-dose openlabel randomized sequence crossover studies evaluated the bioavailability of eltrombopag when administered with different foods, fat levels, calcium levels, and antacids. Men receiving a high calcium diet with administration of eltrombopag had a $59 \%$ reduction in bioavailability and those administered a metal cation-containing antacid had a $70 \%$ reduction. ${ }^{77}$ Current guidelines recommend taking this medication on an empty stomach to enhance bioavailability. ${ }^{65}$

Overall, eltrombopag appears to be a well-tolerated therapeutic option for patients with chronic refractory ITP and has shown to have short and long-term benefits for increasing platelet counts to safer levels and reducing the occurrence of bleeding events with relatively mild adverse effects (Table 2). Its efficacy is similar to that of romiplostim and affords an alternative agent in this class of medications.

\section{Quality of life in patients using TPO mimetic agents}

The focus of ITP typically revolves around the etiology, mechanisms, and treatment of the disease. Often, the quality of a patient's life, who is suffering from chronic ITP, is overlooked. ITP is often considered a benign disease, yet health-related quality of life is frequently reported as poor. ${ }^{78}$ The symptoms and treatment of ITP can have a significant impact on a person's daily functioning. Likewise, there are psychological components, such as fear of bleeding, body image, fear of surgery, and medication side effects which may have a negative influence on the patient's life. A study of 73 adult patients with chronic ITP was performed to assess the impact of the disease via a self-reported, health-related, quality of life questionnaire. ${ }^{78}$ The questionnaire assessed 8 components of quality of life including physical functioning and role, bodily pain, general health, vitality, emotional role, social functioning, and mental health. It compared results of ITP patients to those without disease, with a different chronic disease, and those receiving medications or not. Results revealed that patients with ITP had a diminished sense of quality of life compared to healthy individuals, similar quality to those with chronic diseases such as diabetes or arthritis, with results mildly more positive in those not receiving medical therapy for their disease.

Patients receiving romiplostim were evaluated during the open-label extension study using a double-blind, placebocontrolled environment. This study also included assessment of those who were able to self-inject. ${ }^{79}$ Patients completed a 
new 44 question ITP-patient assessment questionnaire, the first of its kind, at baseline and at each scheduled visit to assess quality of life, burden of disease, as well as outcome measurement after treatment. ${ }^{13,80}$ At baseline, scores were comparable between the treatment and placebo groups. Although splenectomized patients reported a lower baseline quality of life when compared to nonsplenectomized patients, both groups reported improvements when compared to placebo groups after treatment with romiplostim, though splenectomized patients still reported lower values when compared to nonsplenectomized. At 24 weeks, those who did not respond to romiplostim had decreased values in psychological health questions. Patients who continued on their concurrent medications had lower scores but there were no statistical differences determined.

A large survey conducted in the United Kingdom assessed health-related lifestyle among 790 adults and children with ITP. The study revealed that one quarter of adults and one fifth of children reported missing work or school due to fatigue from ITP. Many proclaimed to have difficulty obtaining insurance while others admitted to having elective surgical procedures delayed as a result of low platelets. Adults and children admitted to being suspected of subjection to violence due to the many bruises from their illness. ${ }^{81}$

Another North American survey conducted to assess patients' willingness to accept certain risks or adverse events to increase the likelihood of treatment success, avoid the need for corticosteroids, or obtain a convenient mode of administration was completed by 1542 patients with chronic ITP. To obtain a $25 \%$ increase in likelihood of achieving an appropriate platelet count, patients were willing to accept an $18.8 \%$ risk for rebound thrombocytopenia. To avoid the use of steroids, patients accepted a $20 \%$ risk for rebound thrombocytopenia and $3.4 \%$ risk of blood clot. Interestingly, patients were willing to accept a $2 \%$ risk of thrombotic event and a $13 \%$ risk of liver function test abnormalities or rebound thrombocytopenia if they could take 1-2 pills per day in place of going to a physician office weekly for an injection. In fact, $71 \%$ of patients stated they would choose pills over injections in general. ${ }^{25}$

\section{Conclusion}

To date, long-term management of chronic, refractory ITP has been less than satisfactory due to the variable efficacy, poor tolerability, and severe side effects associated with current treatment options. ${ }^{25}$ As evidenced from many healthrelated quality of life surveys, patients are often troubled not only by the medical complications of this disease but also the social and psychological impacts. Traditional first line therapies for adult chronic ITP are still important agents that provide long-term improvements in the majority of patients, but they do have their associated adverse effects. Patients with relapsing or refractory disease are more likely to be affected by toxicities due to the prolonged use. With the addition of the TPO-mimetic drugs, romiplostim and eltrombopag as treatment options, patients now have an alternative to previous therapies. It is important to note that these therapies are primarily studied in patients with chronic refractory disease who have failed many other treatments. These medicines are not designed to be curative and their place in earlier treatment of ITP has yet to be established. ${ }^{82}$ On the whole, however, these medications appear to be promising, effective, and well-tolerated therapeutic agents with the potential to improve quality of life and reduce the therapy-related toxicities in the treatment of chronic, refractory immune thrombocytopenic purpura.

\section{Disclosures}

The authors report no conflicts of interest in this work.

\section{References}

1. Cines DB, Blanchette VS. Immune thrombocytopenic purpura. $N$ Engl J Med. 2002;346(13):995-1008.

2. George JN, Woolf SH, Raskob GE, et al. Idiopathic thrombocytopenic purpura: a practice guideline developed by explicit methods for the American Society of Hematology. Blood. 1996;88(1):3-40.

3. Frederiksen H, Schmidt K. The incidence of idiopathic thrombocytopenic purpura in adults increases with age. Blood. 1999;94(3):909-913.

4. Rodeghiero F, Stasi R, Gernsheimer T, et al. Standardization of terminology, definitions, and outcome criteria in immune thrombocytopenic purpura of adults and children: report from an international working group. Blood. 2009;113(11):2386-2393.

5. Fogarty PF, Segal JB. The epidemiology of immune thrombocytopenic purpura. Curr Opin Hematol. 2007;14(5):515-519.

6. Schoonen WM, Kucera G, Coalson J, et al. Epidemiology of immune thrombocytopenic purpura in the General Practice Research Database. Br J Haematol. 2009;145(2):235-244

7. Neylon AJ, Saunders PW, Howard MR, et al. Clinically significant newly presenting autoimmune thrombocytopenic purpura in adults: a prospective study of a population-based cohort of 245 patients. $B r J$ Haematol. 2003;122(6):966-974.

8. Feudjo-Tepie MA, Robinson NJ, Bennett D. Prevalence of diagnosed chronic immune thrombocytopenic purpura: analysis of a large US claim database: a rebuttal. J Thromb Haemost. 2008;6(4):711-712.

9. Segal JB, Powe NR. Prevalence of immune thrombocytopenic purpura: analysis of administrative data. J Thromb Haemost. 2006;4:2377-2383.

10. Portielje JE, Westendorp RG, Kluin-Nelemans HC, Brand A. Morbidity and mortality in adults with idiopathic thrombocytopenic purpura. Blood. 2001;97(9):2549-2554.

11. Danese MD, Lindquist K, Gleeson M, Deuson R, Mikhael J. Cost and mortality associated with hospitalizations in patients with immune thrombocytopenic purpura. Am J Hematol. 2009;84(10):631-635.

12. Terrell D, Beebe LA, Mold JW, George J, Vesely SK. What level of platelet count and symptoms trigger referral of patient with thrombocytopenic from primary care physicians to hematologists? Blood. (ASH Annual Meeting Abstracts) 2008;112:4692. 
13. George JN, Mathias SD, Go RS, et al. Improved quality of life for romiplostim-treated patients with chronic immune thrombocytopenic purpura: results from two randomized, placebo-controlled trials. $\mathrm{Br} \mathrm{J}$ Haematol. 2009;144(3):409-415.

14. Stasi R, Evangelista ML, Stipa E, Buccisano F, Venditti A, Amadori S. Idiopathic thrombocytopenic purpura: Current concepts in pathophysiology and management. Thromb Haemost. 2008;99(1):4-14.

15. Cines DB, Bussel JB, Liebman HA, Luning Prak ET. The ITP syndrome: pathogenic and clinical diversity. Blood. 2009;113:6511-6521.

16. Cines DB, McMillan R. Pathogenesis of chronic ITP. Curr Opin Hematol. 2007;14(5):511-514.

17. McMillan R, Wang L, Tomer A, Nichol J, Pistillo J. Suppression of in vitro megakaryocyte production by anti-platelet antibodies from adults patients with chronic ITP. Blood. 2004;103:1364-1369.

18. Fabris F, Scandalleri R, Ruzzon E, et al. Platelet-associated antibodies as detected by a solid-phase modified antigen capture ELISA test (MACE) are a useful prognostic factor in idiopathic thrombocytopenic purpura. Blood. 2004;103(12):4562-4564.

19. McMillan R. The role of antiplatelet antibody assays in the diagnosis of immune thrombocytopenic purpura. Curr Hematol Rep. 2005;4(2): $160-165$.

20. Stasi R, Provan D. Management of immune thrombocytopenic purpura in adults. Mayo Clin Proc. 2004;79:504-522.

21. Stevens W, Koene H, Zwaginga JJ, Vreugdenhil G. Chronic idiopathic thrombocytopenic purpura: present strategy, guidelines and new insights. Neth J Med. 2006;64(10):356-363.

22. Cines DB, Bussel JB. How I treat idiopathic thrombocytopenic purpura (ITP). Blood. 2005;106:2244-2251.

23. Cheung E, Liebman HA. Anti-RhD immunoglobulin in the treatment of immune thrombocytopenia. Biologics. 2009;3:57-62.

24. George JN, Raskob GE, Vesely SK, et al. Initial management of immune thrombocytopenic purpura in adults: a randomized controlled trial comparing intermittent anti-D with routine care. Am J Hematol. 2003; $74: 161-169$.

25. Grotzinger KM, Johnson FR, Hauber AB, Ozdemir S, Bala MV. Patients are willing to trade off efficacy, safety, and administration attributes of chronic idiopathic purpura (ITP) therapy: results from a large North American discrete choice study. Blood. (ASH Annual Meeting Abstract) 2008; 112:669.

26. Kojouri K, Vesely SK, Terrell DR, George JN. Splenectomy for adult patients with idiopathic thrombocytopenic purpura: a systematic review to assess long-term platelet count responses, prediction of response, and surgical complications. Blood. 2004;104(9):2623-2634.

27. Mikhael J, Northridge K, Lindquist K, Kessler C, Deuson R, Danese M. Short-term and long-term failure of laparoscopic splenectomy in adult immune thrombocytopenic purpura: A systematic review. Am J Hematol. 2009;84(11):743-748.

28. Arnold DM, Nazi I, Santos A, et al. Combination immunosuppressant therapy for patients with chronic refractory immune thrombocytopenic purpura. Blood. 2010;115(1):29-31.

29. Arnold DM, Francesco D, Crowther MA, et al. Systematic review: efficacy and safety of Rituximab for adults with idiopathic thrombocytopenic purpura. Ann Intern Med. 2007;146:25-33.

30. Sreenivasappa SB, Catchatourian R, Yim B. Risk profile, efficacy and safety of Rituximab in patients with relapsed or refractory idiopathic thrombocytopenic purpura in a minority cohort with long-term follow up. Blood. (ASH Annual Meeting Abstracts) 2008; 112:4546.

31. Zaja F, Baccarani M, Mazza P, et al. A prospective randomized study comparing Rituximab and Dexamethasone Vs Dexamethasone alone in ITP: results of final analysis and long-term follow up. Blood. (ASH Annual Meeting Abstracts) 2008;112:1.

32. Ballem PJ, Segal GM, Stratton JR, Gernsheimer T, Adamson JW, Slichter SJ. Mechanisms of thrombocytopenia in patients with chronic autoimmune thrombocytopenic purpura. Evidence of impaired platelet production and increased platelet clearance. J Clin Invest. 1987;80(1):33-40.
33. Cohn CS, Bussel JB. Romiplostim: a second-generation thrombopoietin agonist. Drugs Today. 2009;45(3):175-188

34. Vigon I, Mornon J, Cocault L, et al. Molecular cloning and characterization of MPL, the human homolog of the v-mpl oncogene: identification of a member of the hematopoietic growth factor receptor superfamily. Proc Natl Acad Sci U S A. 1992;89(12):5640-5644.

35. Perreault S, Burzynski J. Romiplostim: a novel thrombopoiesisstimulating agent. Am J Health Syst Pharm. 2009;66(9):817-824.

36. Kosugi S, Kurata Y, Tomiyama Y, et al. Circulating thrombopoietin levels in chronic immune thrombocytopenic purpura. Br J Haematol. 1996;93(3):704-706.

37. Aldort LM, Hayward CP, Chen MG, Nichol JL, Bussel J; ITP Study Group. Prospective screening of 205 patients with ITP, including diagnosis, serological markers, and the relationship between platelet counts, endogenous thrombopoietin, and circulating antithrombopoietin antibodies. Am J Hematol. 2004;76:205-213.

38. Wendling F, Maraskovky E, Debili N, et al. CMPL ligand is a humoral regulator of megakaryocytopoiesis. Nature. 1994;369:571-574.

39. Nurden AT, Viallard JF, Nurden P. New generation drugs that stimulate platelet production in chronic immune thrombocytopenic purpura. Lancet. 2009;373:1562-1569.

40. Kuter DJ. New thrombopoietic growth factors. Blood. 2007;109(11): $4607-4617$

41. Nomura S, Dan K, Hotta T, Fujimura K, Ikeda Y. Effects of pegylated recombinant human megakaryocyte growth and development factor in patients with idiopathic thrombocytopenic purpura. Blood. 2002;100:728-730.

42. Li J, Yang C, Xia Y, et al. Thrombocytopenia caused by the development of antibodies to thrombopoietin. Blood. 2001;98(12):3241-3248.

43. Cwirla SE, Balasubramanian P, Duffin DJ, et al. Peptide agonist of the thrombopoietin receptor as potent as the natural cytokine. Science. 1997;276:1696-1699.

44. Rice L. Treatment of immune thrombocytopenic purpura: focus on eltrombopag. Biologics. 2009;3:151-157.

45. Broudy VC, Lin NL. AMG 531 stimulates megakaryopoiesis in vitro by binding to Mpl. Cytokine. 2004;25(2):52-60.

46. Amgen Inc., Nplate ${ }^{\circledR}$ (Romiplostim) for subcutaneous injection. Prescribing information. Available from URL: http://www.nplate.com. Accessed 2009 Sep 20.

47. Thompson CA. FDA approves thrombopoiesis-stimulating agent. Am J Health Syst Pharm. 2008;65(19):1788.

48. Perugini M, Varelias A, Sadlon T, D’Andrea RJ. Hematopoietic growth factor mimetics: From concept to clinic. Cytokine Growth Factor Rev. 2009;20(1):87-94.

49. Wang B, Nichol JL, Sullivan JT. Pharmacodynamics and pharmacokinetics of AMG 531, a novel thrombopoietin receptor ligand. Clin Pharmacol Ther. 2004;76(6):628-638.

50. Jawa V, Hokom M, Hu J, et al. Low immunogenicity to romiplostim in clinical studies with ITP subjects. Blood. (ASH Annual Meeting Abstracts) 2008;112:3425.

51. Newland A, Caulier MT, Kappers-Klunne M, et al. An open-label, unit dose-finding study of AMG 531, a novel thrombopoiesis-stimulating peptibody, in patients with immune thrombocytopenic purpura. $\mathrm{Br} J$ Haematol. 2006;135(4):547-553.

52. Bussel JB, Kuter DJ, Geroge JN, et al. AMG 531, a thrombopoiesisstimulating protein, for chronic ITP. $N$ Engl J Med. 2006;355: 1672-1681.

53. Shirasugi Y, Ando K, Hashino S, et al. A phase II, open-label, sequential-cohort, dose-escalation study of romiplostim in Japanese patients with chronic immune thrombocytopenic purpura. Int J Hematol. 2009;90:157-165.

54. Kuter DJ, Bussel JB, Lyons RM, et al. Efficacy of romiplostim in patients with chronic immune thrombocytopenic purpura: a doubleblind randomized controlled trial. Lancet. 2008;371:395-403.

55. Bussel JB, Kuter DJ, Pullarkat V, Lyons RM, Guo M, Nichol JL. Safety and efficacy of long-term treatment with romiplostim in thrombocytopenic patients with chronic ITP. Blood. 2009;113:2161-2171. 
56. Pullarkat VA, Gernsheimer TB, Wasser JS, et al. Quantifying the reduction in immunoglobulin use over time in patients with chronic immune thrombocytopenic purpura receiving romiplostim (AMG 531). Am J Hematol. 2009;84(8):538-540.

57. Tarantino M, Sunkara U, George J, et al. Evaluation of bleeding and thrombotic events during long-term use of romiplostim in patients with chronic immune thrombocytopenic purpura. Blood. (ASH Annual Meeting Abstracts) 2008;112:3422.

58. Kuter DJ, Mufti GJ, Bain BJ, Hasserjian RP, Davis W, Rutstein M. Evaluation of bone marrow reticulin formation in chronic immune thrombocytopenia (ITP) patients treated with romiplostim. Blood. 2009;114(18):3748-3756.

59. Kuter DJ, Bain BJ, Mufti GJ, Bagg A, Hasserjian RP. Bone marrow fibrosis pathophysiology and clinical significance of increased bone marrow stromal fibres. Br J Haematol. 2007;139(3):351-362.

60. Ikeda Y, Miyakawa Y. Development of thrombopoietin receptor agonist for clinical use. J Throm and Haemost. 2009;7(1):239-244.

61. Frampton JE, Lyseng-Williamson KA. romiplostim. Drugs. 2009;69(3):307-317.

62. Two new drugs for chronic ITP. Med Lett Drugs Ther. 2009;51(1305): $10-11$.

63. Iperna HJ, Jung MY, Lodolce AE. Romiplostim management of immune thrombocytopenic purpura. Ann Pharmacother. 2009;43:914-919.

64. GlaxoSmithKline. Promacta (eltrombopag tablets): US prescribing information. (online). Available from URL: http://www.promactacares. com/prescribing_information.pdf. (Accessed 2009 Sep 20).

65. Garnock-Jones KP, Keam SJ. Eltrombopag. Drugs. 2009;69(5): 567-576.

66. Erickson-Miller CL, Delorme E, Tian SS, et al. Preclinical activity of eltrombopag (SB-497115) an oral, nonpeptide thrombopoietin receptor agonist. Stem Cells. 2009;27(2):424-430.

67. Erhardt JA, Erickson-Miller C, Aivado M, Abboud M, Pillarisetti K, Toomey JR. Comparative analyses of the small molecule thrombopoietin receptor agonist eltrombopag and thrombopoietin on in vitro platelet function. Exp Hematol. 2009;37(9):1030-1037.

68. Jenkins JM, Williams D, Deng Y, et al. Phase 1 clinical study of eltrombopag, an oral, nonpeptide thrombopoietin receptor agonist. Blood. 2007;109:4739-4741.

69. Bussel JB, Cheng G, Saleh MN, et al. Eltrombopag for the treatment of chronic idiopathic thrombocytopenic purpura. $N$ Engl J Med. 2007;357:2237-2247.

70. Bussel JB, Provan D, Shamsi T, et al. Effect of eltrombopag on platelet counts and bleeding during treatment of chronic idiopathic thrombocytopenic purpura: a randomized, double-blind, placebo-controlled trial. Lancet. 2009;373:641-648.
71. Bussel JB, Cheng G, Saleh MN, et al. Safety and efficacy of long-term treatment with oral eltrombopag for chronic idiopathic thrombocytopenic purpura. Blood. (ASH Annual Meeting Abstracts) 2008;112:3432.

72. Bussel JB, Psaila B, Saleh MN, et al. Efficacy and safety of repeated intermittent treatment with eltrombopag in patients with chronic idiopathic thrombocytopenic purpura. Blood. (ASH Annual Meeting Abstracts) 2008;112:3431

73. Saleh MN, Bussel JB, Cheng G, et al. Eltrombopag is efficacious in patients with refractory chronic idiopathic thrombocytopenic purpura (ITP)-Data from the EXTEND study. Blood. (ASH Annual Meeting Abstracts) 2008;112:401.

74. Fogarty PF, Bussel JB, Cheng G, et al. Oral eltrombopag treatment reduces the need for concomitant medications in patients with chronic idiopathic thrombocytopenic purpura. Blood. (ASH Annual Meeting Abstracts) 2008;112:3424.

75. Cheng G, Bussel JB, Saleh MN, et al. Eltrombopag delivers clinical benefit in chronic idiopathic thrombocytopenia purpura (ITP) patients not achieving platelet counts $\geq 50,000 / \mu \mathrm{L}$ - Data from the EXTEND study. Blood. (ASH Annual Meeting Abstracts) 2008;112:3430.

76. Cheng G, Salah MN, Bussel JB, et al. Oral eltrombopag for the longterm treatment of patients with chronic idiopathic thrombocytopenic purpura: results of a Phase III, double-blind, placebo-controlled study (RAISE). Blood. (ASH Annual Meeting Abstracts) 2008;112:400.

77. Williams DD, Peng B, Bailey CK, et al. Effects of food and antacids on the pharmacokinetics of eltrombopag in healthy adult subjects: two single-dose, open-label, randomized-sequence, crossover studies. Clin Ther. 2009;31(4):764-776.

78. McMillan R, Bussel JB, George JN, Lalla D, Nichol JL. Self-reported health-related quality of life in adults with chronic immune thrombocytopenic purpura. Am J Hematol. 2008;83(2):150-154.

79. George JN, Bussel JB, Lyons RM, et al. Self-injection of romiplostim by patients with chronic immune thrombocytopenic purpura (ITP). Blood. (ASH Annual Meeting Abstracts) 2008;112:4707.

80. Mathias SD, Bussel JB, George JN, McMillan R, Okano GJ, Nichol JL. A disease-specific measure of health-related quality of life in adults with chronic immune thrombocytopenic purpura: psychometric testing in an open-label clinical trial. Clin Ther. 2007;29(5):950-962.

81. Sarpatwari A, Watson S, Anderson H, Provan D, Newland A. Healthrelated lifestyle among adults and pediatric patients with idiopathic thrombocytopenic purpura in the United Kingdom. Blood. (ASHAnnual Meeting Abstracts) 2008;112:3435.

82. Cines DB, Yasothan U, Kirkpatrick P. Romiplostim. Nat Rev Drug Discov. 2008;7(11):887-888.

Journal of Blood Medicine

\section{Publish your work in this journal}

The Journal of Blood Medicine is an international, peer-reviewed, open access, online journal publishing laboratory, experimental and clinical aspects of all topics pertaining to blood based medicine including but not limited to: Transfusion Medicine; Blood collection, Donor issues, Transmittable diseases, and Blood banking logistics; Immunohematology; Artificial and alternative blood

\section{Dovepress}

based therapeutics; Hematology; Biotechnology/nanotechnology of blood related medicine; Legal aspects of blood medicine; Historical perspectives. The manuscript management system is completely online and includes a very quick and fair peer-review system. Visit http://www.dovepress.com/ testimonials.php to read real quotes from published authors. 